\title{
A interacción do aquí e do acolá na obra de Manuel Pereira Valcárcel
}

\author{
The Interaction between Here and Over There in \\ Manuel Pereira Valcárcel's Work
}

\author{
María Curros Ferro \\ Universidad de Granada \\ Centro de Estudos Galegos \\ mcurfer@ugr.es
}

[recibido 26/10/2014, aceptado 26/01/2015]

\section{RESUMO}

A obra de Manuel Pereira Valcárcel é un diario de notas, unha viaxe iniciática desde o seu Ouzande natal a Madrid. A súa poesía de carácter intimista permite que o lector se introduza no seu interior. É a propia medra a que está en xogo para non ser devorada pola grande urbe. A mellora atravesa as fronteiras do alá e a mocidade fica lonxe.

PALABRAS CHAVE: Manuel Pereira, poesía galega, tempo, lembranzas, viaxes.

\section{RESUMEN}

La obra de Manuel Pereira Valcárcel es un diario de notas, un viaje iniciático desde su Ouzande natal a Madrid. Su poesía de carácter intimista permite la introducción del lector en su interior. Es el crecimiento personal el que está en juego para así no ser devorado por la gran urbe. La mejora del individuo atraviesa las fronteras del allá y la juventud ha quedado lejos.

PALABRAS ClAVE: Manuel Pereira, poesía gallega, tiempo, memorias, viajes.

\section{ABSTRACT}

Manuel Pereira Valcárcel's work is a diary which reflects his first journey from his home town of Ouzande to Madrid. His intimist poetry reveals his innermost character. His own personal development became the author's main priority as well as trying to avoid being consumed living in such a large city. The author's personal improvement crosses frontiers and he loses his youth in the process.

KEY WORDS: Manuel Pereira, Galician poetry, time, memories, journeys.

Curros Ferro, M. (2015): “A interacción do aquí e do acolá na obra de Manuel Pereira Valcárcel”, Madrygal (Madr.), 18, Núm. Especial: 411-420.

SUMARIO: 1. Introdución. 2. Poemas de cinza. 3. Todo morte. 4. Rosa intima. 5. Inventario de fragmentos. 6. Libro das viaxes. 7. Tatuaxes. 8. Interior con froiteiro e feridas. 9. Traxectos curtos. 10. Días do final. 11. Malas cartas. 12. Conclusión. 13. Referencias bibliográficas. 


\section{INTRODUCIÓN}

A obra de Manuel Pereira Valcárcel é a interacción entre o espazo e mais a viaxe. Desde Poemas de cinza (1990) ata a súa derradeira obra, Malas cartas (2010), atópanse odiseas, periplos, desprazamentos. Ás veces o destino dise explicitamente, outras debe o lector imaxinalo. A terra da que parte adoita ser Galicia porque en poucos autores vida e obra van aparecer tan ligados coma na do mestre Pereira. A través dos seus escritos chégase ao seu corazón, pero tamén se permite a aproximación aos seus pensamentos, que son aquí os de quen razoa e vive o que escribe. Este traballo é un modo de achegarse á "interacción do aquí e do acolá na súa obra”, porque existe unha íntima relación entre a creación e o autor.

\section{POEMAS DE CINZA}

O libro Poemas de cinza componse de varias partes, en concreto catro: 1. Inicios, 2. Desacougo, 3. Amor e desamor e 4. Poemas de amor cotián. O fío condutor son os recordos, as imaxes na memoria. Foi escrito en Madrid entre marzo e agosto de 1987 e a súa temática xa adianta a doutras obras posteriores. Moitos dos poemas teñen dedicatoria, outros non, o que non deixa de ser relevante polo que se verá máis adiante. A cidade e o asfalto convértense en protagonistas da análise da paisaxe urbana.

É a relación de recordos que bailan na memoria. Pero tamén o desacougo, a axitación de quen sabe que o pasado fuxiu, que aqueles tempos da nenez na escola e na aldea non van volver máis. As descricións do mundo dos labregos, da vida dos campesiños, antes rexeitados por distintos motivos, agora presentes, opóñense aos rañaceos e ás paredes. Agora todo é chuvia de bágoas en noites marcadas polo silencio, escuridade que recorda a lama dos camiños, noite que non fai senón que medren sentimentos que repudian os espazos escuros. Algúns poemas non levan título, outros si. Velaquí un exemplo (Pereira Valcárcel 1990: 27):

Non é que esteamos sós

Porque as rúas estén baleiras:

É que a xente que pasa

A carón de nós

Son rostros alleos.
Dalgunha maneira, este libro de poemas fai lembrar o lector a Longa noite de pedra de Celso Emilio Ferreiro, aínda que con trazos distintos. As noites son as pedras porque se sofren na urbe; noites que non deixan acougar, durmir. Os días nacen mortos, polo que as noites non teñen vida. Os primeiros amores de xuventude mestúranse co asfalto na cidade. O título Poemas de cinza xa o di todo, borralla que queda da vida pasada. Aínda con todo, o libro péchase cun fío de optimismo, o gozo da vellez xunto aos nosos.

\section{TODO MORTE}

Publicado inicialmente en 1998 e reeditado en 2006, este libro de poemas achega o lector á fin da vida; de feito, esta obra ben podería considerarse un canto á morte. Amais, dedícaselle unha parte do libro a un familiar: a un irmán. Algúns dos poemas carecen de signos de puntuación, o que lles confire certa anguria, como se ao lelos foramos quedar sen folgos. Esa inquedanza que transmite a voz poética produce e orixina desesperanza e derrota. A única voz que escoitamos ao lermos estes versos é a morte, aínda que non fala en primeira persoa:
Vén de lonxe,
Trae a medida
De todas as idades,
É temperá
Ou serodia,
É dúbida
Ou sentenza,
É ferro
Ou sono. (Pereira Valcárcel 2006: 19)

A morte, veña coas guerras ou coas doenzas, require e non espera a ninguén. Témeselle porque deixa sen contos as casas familiares. O tema é recorrente na historia da literatura, pois encontrámolo xa no Antigo Exipto, en textos funerarios coma $O$ libro dos mortos. $\mathrm{O}$ ben e o mal e a vida e a morte camiñan por esta obra sen deixar indiferente o lector. A morte, nalgúns destes poemas, aproveita para sacar á luz o tema das guerras. É aquí onde, se cadra, se producen as mortes máis inxustas. Hai asasinatos que, dalgún modo, tamén translocen a mesma senrazón. O que envolve ao cabo o ser humano é o falecemento. Adoita ser, ademais, 
un elemento literario que se emprega, así mesmo, para falarmos doutros temas coma o tempus fugit ou a adversidade. Xa o dicía Jorge Manrique en Coplas a la muerte de su padre:

Nuestras vidas son los ríos que van a dar en la mar, qu'es el morir.

Pero volvendo a Todo morte, non se debe deixar de sinalar que atopamos o paso do tempo, entre outros, no cambio cíclico das estacións:

Como conclúe un verán

Como afogan as ambicións perseguidas

Como declina a fráxil gloria dos guerreiros [anónimos

Ou como desaparece a fe nun deus que xa

(Pereira Valcárcel 2006: 69) [non cremos.

A relixión tampouco se lle escapa a Manuel Pereira Valcárcel na súa obra, pois camiña xunto á morte. Cando os cristiáns xa non teñen o consolo porque deixaron de crer, que lles queda? Talvez poidan pensar na vida e na morte coma se fosen ambas as dúas caras dunha moeda. En ocasións, o ser humano precisa do falecemento dun ser querido para se dar de conta de que somos vulnerables e de que a vida, como diría Castelao, "é prestada". Desta maneira, o finamento prematuro da nai do autor puido ser o pulo que o levou a escribir Todo morte. O ser humano, aínda que o intente, nunca estará preparado para agardar a morte, malia que se trate dunha realidade máis dos seres vivos.

\section{ROSA ÍNTIMA}

Aínda que publicado en 2000, segundo nolo fai constar o autor parece que foi escrito durante máis dunha década, a cabalo entre Ouzande e Madrid. Fan a súa aparición, de novo, as estacións: inverno, verán, outono e primavera, símiles que identifican o tempo e a vida, que transcorre e non volve. Xunto ao tempus fugit que atopabamos en Todo morte, neste libro de poemas encontramos o amor, tema que enche a creación literaria universal, outro gran clásico na obra de Manuel.
Fuxir sempre

E ir a ti.

Comezar sempre

E iniciar contigo

A viaxe.

Poder elixir

E elixirte a ti.

(Pereira Valcárcel 2000: 23)

Mar e amor recorren as páxinas deste libro e, xunto a eles, o sexo, que fai da vida lume, fume, situación que desacouga. O amor é unha viaxe cara a un mundo idílico, incrible.

Camiñarte, areal sereno, praia
Onde os meus desvelos buscan o verán
E un ceo inquedo de gaivotas
Navegarte, sucar as túas augas
En desexada singradura
Entrar en ti, salgada escuridade,
Con ímpeto de faro
Na noite mariña.
(id. 53 )

Aínda con todo, cara ao final, en Rosa intima tamén se encontran elementos que protagonizaban os anteriores libros de poemas coma as descricións de días cotiás, os primeiros amores, as promesas esquecidas que algún día foron soños... A poesía de Manuel Pereira é amor, morte, tempo que escorrega coma árbores nas ladeiras. O lector consegue converterse nun mergullador que nada cara á interioridade da vida humana para se decatar de que o desexo é percorrer xuntos a viaxe eterna da vida. Para iso hai que compartir ese percorrido empregando o mesmo medio de transporte, a palabra. De aí que a voz poética faga explícita a súa necesidade: o corpo nu dela.
Íspete
E que a noite
Chova
Amor
Sobre a túa pel.
(id. 43)

Os poemas fanse lenzos nas páxinas que o lector devora coa mirada. Os elementos da natureza inundan coas súas cores as sensacións que suxiren ata chegar á cognición de obxectos que sempre foron irredentos. 
Paixón,

Papoula que

Arde

Na seara perenne

Do desexo.

(id. 46)

Moitos dos poemas deste libro presentan matices claramente intimistas e sexuais. Velaquí neste fragmento o verso que dá título ao libro:

Recendos escondidos
Gozosas voces
Nocturnas liturxias
Chámanme
Dende a túa
Rosa íntima
Entrar en ti, salgada escuridade,
Con ímpeto de faro
Na noite mariña.
(id. 49 )

Como se pode observar, a descrición do acto sexual e a viaxe amatoria son unha constante nestes poemas.

Pétalos
Onde
Esmorece
A miña
Ansiedade
Rota
En seme.
(id. 55)

\section{INVENTARIO DE FRAGMENTOS}

A seguinte obra do mestre Pereira retoma o tema da morte. Inventario de fragmentos, publicado en 2001, non é propiamente un libro de poemas, senón de relatos de prosa poética. Por ser un tema eterno e atemporal, a morte atopámola en todas as culturas, en todas as literaturas e en todas as obras de Manuel Pereira coma se fose unha obsesión. A miúdo, cando se trata este tema o ser humano acaba por reflectir así o inefable. Fálase da morte, pero ata que punto podemos coñecer o máis alá se os que xa marcharon do mundo dos vivos non volveron? Con todo, a morte nos libros do estradense acaba por deixar certo pouso de inquedanza nos lectores.
Desigual combate contra as armas Obsesivas da morte. Nembargantes Seguir, coma un vagalume na noitebra, Coma unha folla no vendaval, coma un Boneco sen arrolos.

(Pereira Valcárcel 2001: 16)

Aprécianse os trazos artísticos da defunción porque ao chegar a este estado xérase no corpo unha conversión: "boneco sen arrolos". Pero por riba de todo a poesía de Pereira Valcárcel é a realidade do ser humano reflectíndoa en todos os sentidos, dándolle espírito, contido artístico.

Ser algo no corazón de alguén, ser o motivo dunha viaxe, dun sorriso, dun xesto. Ser para outro o que non estamos

(id. 52) [seguros de ser para nós.

A poesía concédelle ao autor a posibilidade de viaxar, de se desprazar, converténdoa na súa realidade cotiá. Como quedou dito, son as súas propias vivencias. Nunha entrevista recente confirmábao o estradense: “eu, de feito, case todos os anos vou a Asturias, case todos os anos vou a Zaragoza, vivo en Madrid e, por suposto, todos os anos vou a Galicia tres ou catro veces. Eu son unha persoa moi fiel ás persoas e aos lugares, mesmo aos obxectos" (Regueiro Salgado 2014: 258). Poderíase entender que vive nun eterno desprazamento porque lle obsesiona. Ao cabo, os seus recordos son duais xa que os da aldea acaban por se confrontar aos da cidade:

Congostras e bidueiros, devesas e faiados, centeo e lama. A aldea, unha esmeralda luxada na memoria.

(id. 70)

Co grao de realismo propio da súa Galicia natal, atópanse unhas descricións moi precisas de itinerarios e comarcas que nos trasladan a este lugar. Son, sobre todo, lembranzas, mais non por iso se lles pode quitar o trazo da fidelidade da translación da paisaxe ao poema. Ás veces esa paisaxe, descrita maxistralmente, é identificada coa voz amiga. $\mathrm{Na}$ obra de Manuel Pereira Valcárcel non falta a man do camarada, do compañeiro co que adoita xogar a través da mirada, da voz, en 
definitiva, dos sentidos. Fundamentalmente a súa poesía caracterízase polos elementos sensoriais que identifica cos do amigo cómplice e apoio constante. Case non hai carencias de voces queridas, agás cando nas viaxes se impón a distancia. Daquela, si que atopa o lector un burato, pois a intimidade entre as persoas vólvese imprescindible tal como queda nestes relatos demostrado. Sen a mirada do outro, sen a verdadeira amizade, á vida faltaríalle todo; de aí que o enriquecemento persoal sexa quen de desenvolver ese inventario de fragmentos que temos por vida.

\section{LIBRO DAS VIAXES}

Unha nova creación sobre periplos e desprazamentos xorde en 2002 con Libro das viaxes. O mar ben podería ser o único protagonista, pois está Galicia nun dos poemas e está tamén América, parte importante dun apartado do libro. Os emigrantes e/ou exiliados chegan a ser os verdadeiros personaxes, mais non os únicos. A morriña inunda cada ángulo dos poemas, aínda que tamén lles proporciona un ápice de esperanza en cada un deles.

As máis difíciles travesías

Cando empezamos a ruta de ida,

Coa ilusión nova e acendida.

Non importan ventos nin marusías,

Non hai obstáculos para a ousadía.

Despois, na singradura de vida,

Pensamos en quén nos dará a benvida

E na doce noite que apague o día.

(Pereira Valcárcel 2002: 10)

Esta viaxe é moitas viaxes; é unha viaxe iniciática, pero tamén é unha viaxe ao pasado. O título do libro reúneas todas. Principalmente é a metáfora que identifica a vida humana como o conxunto de fenómenos que nos ocorren. Como viaxe iniciática pódese pensar no exemplo dos emigrantes galegos que, na procura dun mundo mellor, se subiron ao barco rumbo "ás Américas" (como se denominaba, por extensión, a todos aqueles países dese continente que os acolleron, fundamentalmente Arxentina, Venezuela, Brasil, México e Uruguai). Este tipo de viaxe adoita ter horizonte, loxicamente; unha meta e unha ou unhas etapas. A literatura dá boa conta de exemplos; non esquezamos a Ulises, protagonista da Odisea de Homero. Lembremos, igualmente, que o heroe adoita ter unha misión porque así como a vida é misión, a viaxe tamén o é.

Os avós contaban as súas travesías

Alén do océano.

E nós sucabamos o mar da

Imaxinación en grandes transatlánticos.

(id. 51)

Dalgunha maneira o libro converte o lector nun viaxeiro iniciático porque consegue que reflexione, que madure, para que non esqueza que a viaxe é a busca da verdade, do sentido da nosa existencia. Por este motivo chega a se converter nunha metáfora da vida humana. As viaxes de Manuel Pereira Valcárcel desprázanse cara ao interior, pois non son sempre exteriores e, en ocasións, como se verá, poden chegar a ser oníricas ou ficticias.

Foi bonito.

Durou máis que a maioría dos soños.

Non me pidas que fique aquí.

A eternidade é un xesto fugaz.

Eu non teño outro oficio que andar seguido.

Outros son os que permanecen ou tornan logo. (id. 36)

Atopamos neste Libro das viaxes o interese, o gusto polo traxecto, polo feito de se trasladar dun lugar ao outro, tendencia que se repite e dá título á súa primeira obra en prosa, Traxectos curtos, que será analizada máis adiante.

\section{TATUAXES}

Retomando a orde cronolóxica, encontramos Tatuaxes, que presenta a fixación das impresións vitais na mente humana. Publicado inicialmente en galego no ano 2011, apareceu un ano despois nunha edición bilingüe: galego-español. Así como as tatuaxes modifican a cor da nosa pel onde se crea un debuxo ou calquera tipo de figura, os fenómenos que nos arrodean tamén o fan. Os acontecementos convértense en fluídos que se inxectan na memoria, nos recordos que, ao igual que as tatuaxes na pel, non van desaparecer nunca. Fican aí para sempre manténdose toda a vida 
e acompañándonos ao outro mundo. Non hai láser que posúa total efectividade porque a tinta destas tatuaxes vitais se grava en nós. Do mesmo xeito que se ferra o gando, tatúase a mente humana.

Nostalxia
O pasado
Precipitándose sobre os días amargos.
Semella que todo foi mellor antes
Desta atmósfera doente.
Desta delongada convalecencia.
(Pereira Valcárcel 2012a: 40)

Coa súa "pluma-pincel" (como sinala Vicente Araguas no prólogo), Manuel Pereira vai pintando a súa cidade de acollida, Madrid. Mais o libro Tatuaxes comeza coa reconstrución da súa vida, desde xaneiro de 1974 e desde Ouzande, vila natal. Preséntasenos a relación social e a historia persoal dunha voz poética que atravesa rúas, estacións de metro; en definitiva, Madrid. A identidade vital queda reflectida neste libro de poemas xunto á loita que cada persoa atravesa na súa vida. Camiñamos a través das palabras e dos poemas de Tatuaxes reconstruíndo a vida do autor, interpretando esta obra como diario de a bordo. Rememoramos así a historia persoal, evocada polas sensacións que espertan as figuras, as cores, os cafés... As ferramentas utilizadas ben poderían ser fotografías ou retratos que o pintor traza cun obxectivo: debuxar a imaxe mental da cidade para reflexionar sobre a súa vida. Quen coñeza Madrid e Galicia entenderá a dobre meta que busca plasmar o autor en Tatuaxes. O cotián da grande urbe sérvese de opcións dinámicas que na aldea non se dan, loxicamente. Á vez, esixe atopar sensacións en lugares do espazo que transmiten eses acontecementos históricos que só aí puideron ter lugar.
11 DE MARZO
Vidas esgalladas na cadea
De montaxe dos noticiarios.
No labor vital das ambulancias.
Faltan adxectivos,
Ou talvez sobren,
Para tanto horror.
Masacre, dío todo.
(id. 134)

\section{INTERIOR CON FROITEIRO E FERIDAS}

$\mathrm{O}$ mesmo ano da edición bilingüe de $\mathrm{Ta}$ tuaxes, 2012, publica outro libro de poemas bilingüe, Interior con froiteiro e feridas / Interior con frutero $y$ heridas, acompañado de fermosas ilustracións de Ana Cristina Lapiedra. Neste caso atopámonos con outra obra intimista que, con algunhas diferenzas, garda similitudes coa inmediatamente anterior, $\mathrm{Ta}$ tuaxes. A protagonista é agora Zaragoza, cidade á que Manuel lle debe moito, pois alí pasou, por cuestións familiares, o final da súa nenez. A morriña de tempos pasados alimenta a narración dos poemas. Son os feitos persoais nesta cidade o punto de partida e de reflexión.
O río Ebro, La Pilarica,
As xotas e os cachirulos,
Unha sona de xente túzara,
Tópicos que non fan xustiza,
Nin achegan nada, só esa estúpida
Simpleza dos tópicos.
(Pereira Valcárcel 2012b: 24)

A voz poética a través do espazo e do tempo reconstrúe e relaciona os puntos de encontro analizando a evolución cronolóxica, pero tampouco se esquece dos recordos que, coma en Tatuaxes, fían a historia. Só o paso do tempo permite que reflexionemos sobre o pasado. Os recordos da nenez convértense neste libro en peza fundamental, pois o autor vai na procura da verdade máis íntima. A través da primeira persoa do singular e, noutras ocasións, empregando a primeira persoa do plural, chegamos á etapa das primeiras vivencias, únicas e distintas, porque a terra amada está lonxe e a xente querida tamén. Agora, Zaragoza será o novo chan de acollida, o que dará boa conta da propia vida nunha etapa fundamental, a infancia. Chegamos así ao neno cun profundo carácter retrospectivo. Evocamos lugares, momentos inesquecibles porque

Lémbrote agora e segues sendo perfecta. O tempo non erosiona os recordos, só as [siluetas; Particularmente, as dos corpos que foron [excelsos. (id. 36) 
Por iso volve sempre que pode:

Volver á cidade é comprobar que o tempo

[non o derruba todo,

Que a vida continúa máis alá das tentativas [póstumas.

En cada rúa, nas marxes dos ríos, no centro, [nas aforas,

Segue latexando unha vontade que rexeita o [letargo.

(id. 73)

A infancia que atopamos en Interior con froiteiro e feridas é vivida lonxe do fogar e marcada polos duros acontecementos familiares. Determinada, así mesmo, polos silencios, as complicidades cos compañeiros, os temores... constitúe a experiencia propia da España da posguerra e da ditadura franquista. Os distintos modos de representación veñen determinados, por un lado, pola morriña daquel pasado e, polo outro, pola construción do desenvolvemento da persoa que medra en terra allea. Non podemos esquecer como lectores as motivacións, as vivencias que participan do desenvolvemento da historia desde o comezo ata o final. Asistimos tamén á reconstrución das políticas educativas do momento:

Rapaces e rapazas convenientemente
[separados.

Misa diaria, confesións, penitencia.

Pan con chocolate. Recreos de fútbol e [frontón.

(..)

Os domingos pola tarde cine, un espléndido

Salón de actos. Primeiro as nenas e despois [os nenos.

Películas de romanos exhibindo túnicas,

(id. 16) [cuadrigas, gladiadores.

Recordos e lembranzas que atesouran unha gran cantidade de sensacións vitais que poboan a memoria, coma as tatuaxes do libro de poemas analizado previamente.

\section{TRAXECTOS CURTOS}

Agora cambiamos de xénero da man deste mestre cara a Traxectos curtos (2005), onde a través de relatiños volvemos, de novo, ás viaxes. Trátase da primeira das tres obras en prosa de Manuel Pereira Valcárcel. Movémonos nestes contos xunto a retratos que dan boa conta dos desprazamentos. Ao igual que acontecía nas viaxes das súas obras poéticas, o lector entra así tamén na vida humana dos protagonistas das historias. Dun xeito ou doutro os feitos trasládannos a eses lugares cotiáns da nosa xeografía. A miúdo este tipo de traxectos, chamados curtos, simbolizan máis que a aprendizaxe, as aborrecidas historias de decote. En ocasións son traslados aos lugares de traballo ou idas e vidas á escola; aínda con todo, o coñecemento e a sentenza seguen estando aí presentes. Ben poderían ser chamadas viaxes sociais por estarmos arrodeados de xente, mais non por iso adoita haber nelas diálogo. Algúns medios de transporte non o provocan coma o autobús ou o tren, e menos, incluso, aquel que une a grande urbe coa periferia, o metro. Aínda que ficticios, os traxectos desta obriña ben poderían ser reais.

O Ford Fiesta non estaba no seu mellor momento, pero agora iso non importaba. Seguro que os levaría deica Fisterra e era suficiente. No aparello de música soaba forte, melódico, profundo, Bruce Springsteen. (Pereira Valcárcel 2005: 86)

A través de formas verbais en pasado e de elementos discursivos que precisan a temporalidade e o espazo, percorremos as vidas doutros que poderían ser as nosas. Mais non por iso deixamos de aprender e medramos espiritualmente. Trátase dunha viaxe colectiva que traza un mapa cos distintos tipos de personaxes que a integran. A crítica social e moral dos costumes está presente e tamén a dicotomía campo-cidade, onde a mellora social do traslado a esta última queda patente. $\mathrm{O}$ espazo dos relatos, maioritariamente urbano, ten a súa importancia, mais tamén as historias familiares do fondo que saen á superficie para acabaren por protagonizalas. Porque ao cabo, o que lle interesa a Manuel Pereira é reflectir esa sociedade que nos envolve a todos: sexa cal sexa a nosa idade e habitemos nun punto da terra ou noutro. Por exemplo, a modificación das formas de vida ou a educación operan en Traxectos curtos:

-Dáme cartos, levo o coche, chegarei tarde. Por esta orde. Unha secuencia de lóxica 
impecable. (...) A verdade é que non sei qué queren, tampouco sei en qué nos confundimos, qué fixemos mal. Porque está claro que se eles son así e porque nós os fixemos así. (id. 35)

En definitiva, as viaxes neste libro de relatos son empregadas para falar da vida humana, das súas circunstancias e das súas desventuras.

\section{DÍAS DO FINAL}

Co seguinte libro volvemos dalgún modo a Todo morte, xa que Días do final (2007) nos ofrece unha achega, novamente, ás lembranzas e ao mundo dos mortos, tema universal da biografía humana. Neste caso estamos perante unha noveliña baseada en feitos reais coa que nos introducimos na doenza do pai do protagonista. O tema da enfermidade, fecunda fonte de inspiración ao longo dos séculos, lévanos ás relacións familiares e aos recordos, coma en Tatuaxes. A través da dor e do sufrimento do seu proxenitor o protagonista comeza a facer exame de conciencia e a reflexionar sobre a vida. Expectantes asistimos ao afrontamento da dor, non sendo este só o único tema fundamental na historia, pois a sanidade e a educación tamén se deixan ver. Presenciamos así mesmo a postura de quen ansía para o seu ser querido un final mellor. Coma se foramos partícipes da historia, polo tanto, como testemuñas físicas, logramos introducirnos nela e sufrir coma os personaxes. A mirada coa que explica a situación, o ton, o desenvolvemento dos acontecementos fan que sexa este un relato intimista. Intervén o lector dese padecemento alleo coma se fose propio. De xeito conmovedor e coa beleza do amor e das lembranzas achegámonos á verdade da historia. O autor fai da mirada compasiva unha observación conxunta de sentimentos.

Non te preocupes, isto vai ser lento, aínda non saben ben o que tes, é preciso facer máis probas, despois hanche poñer un tratamento e xa verás como melloras, pero hai para algún tempo aínda no hospital. (Pereira Valcárcel 2007: 22)

Conmóvenos a doenza allea coma se fose propia, porque o autor a través da narración busca a dignidade do lector - a dignidade da condición humana. A calidade do relato apré- ciase pola tenrura coa que son contados os momentos clave, mais tamén a fortaleza daquel que sofre xunto ao doente. Aínda que chea de dor, o poder e o vigor da narración transmiten unha fusión de sensacións cunha amalgama de sentimentos que poboan Días do final.

Había que construír outro treito de rutinas e normalidade. Esixe esforzo e rigor a edificación dos costumes, o establecemento dun ritmo confortable de hábitos. Non é tarefa doada levantar un decorado de vida, fronte á desfeita que se anunciaba. (id. 52)

Esta serie de situacións: estadías no hospital, doenzas dos familiares... levan ao protagonista a pensar na súa propia defunción. Días do final ao cabo reflicte a anguria, a resposta da condición humana fronte á morte, o que nos permite coñecer mellor o mundo. Aprendemos e vivimos con esta novela unha vida que, sen ser a nosa, ben podería selo.

\section{MALAS CARTAS}

Con ela pechamos a análise da creación do estradense por se tratar da súa derradeira obra publicada. Saíu do prelo en 2010 e conta a historia dunha inxustiza: a dun pai de familia acusado dun crime. O lugar onde transcorre a acción é o campo, unha aldea galega de mediados do século XX. América e o tema da emigración volve, de novo, a cobrar protagonismo ao igual que sucedera en Libro das viaxes. A obra deste autor reflicte as idas e regresos na súa vida. Galicia, Madrid, Zaragoza, América... ocupan unha boa parte da súa creación artística, mais tamén do seu legado. Malas cartas, dalgunha maneira, é un canto á sorte, ao azar que xoga un papel crucial nas nosas vidas.

Hai causas de carácter político que fan que Suso, o protagonista da novela, acabe no cárcere, que poderían ser froito da súa situación social. O inculpado é el, aínda que as probas carezan de sustento. De aí que a aventura deste home, unha vez liberado, sexa a "obriga moral" do desprazamento ao estranxeiro, fóra do ámbito vital orixinario, esquivar as críticas da xente da comarca e buscar sustento sendo un foráneo. 
Van alá sete anos. Coma se os levase un río, coma se os enterrase a sombra. Moito tempo dende que embarcara no England Monarch da Mala Real Inglesa no porto de Vigo. Moito tempo de Caracas, Barrio de La Candelaria, cheo de paisanos na procura de vida. (Pereira Valcárcel 2010: 82)

En definitiva, Malas cartas volve a un tema de moito vencello con Galicia: a emigración cara a América. En definitiva, a obra de Manuel Pereira é un produto social que reflicte un fenómeno que chega aos propios escritores, pois o autor non deixa de ser tamén un emigrante que, sempre que pode, volve á súa Galicia natal.

\section{CONCLUSIÓN}

As conclusións ás que se pode chegar tras a lectura dos textos do autor estradense son varias. A función social da creación artística de Manuel Pereira Valcárcel está latente desde o seu primeiro libro, Poemas de cinza, ata a súa derradeira obra ata o momento, Malas cartas. Por unha banda, o autor fotografa de xeito preciso e conciso as grandes realidades sociais do noso tempo: coa conciencia política e económica inserímonos no universo do emigrante, por exemplo en Libro das viaxes. Os continuos cambios na vida persoal de Pereira, que modifican a súa propia fisioloxía humana, aparecen reflectidos na súa produción xunto aos xeográficos, fusionando harmonicamente os espazos, xa que na súa obra non se concibe o tratamento da aldea sen a súa antítese, a cidade; pensemos neste sentido en Tatuaxes ou Inventario de fragmentos. Con frecuencia os lugares abertos opóñense aos pechados, xurdindo así un abano de cores que acaba por proxectar os estados anímicos dos personaxes. Por outra banda, a viaxe e os traxectos forman parte da súa vida desde cativo, polo que acaba por estendelos á súa obra chegando a ser protagonistas de boa parte da súa produción. De feito, a metáfora dos desprazamentos acaba por se converter nun tropo constante que emerxe en situacións cotiás. Con todo, os temas universais como a vida, a morte, as doenzas ou o traballo ocupan un posto destacado na súa produción -que non deixan indiferente a ningún lector-e fainos seus.

Para rematar, non debemos nin podemos esquecer que as súas creacións adoitan ter dedicatorias a seres queridos, familiares, amigos, que dan boa conta da relevancia que todos eles teñen ou tiveron ao longo da súa vida.

\section{REFERENCIAS BIBLIOGRÁFICAS}

LunA, Luis (2010): “A colección “O Roibén”, vieiro de expresión poética do grupo Bilbao", Revista de Lenguas y Literaturas Catalana, Gallega y Vasca 15, pp. 89-101.

(2012): “A colección O Roibén, vieiro de expresión poética do Grupo Bilbao", Revista de Lenguas y Literaturas Catalana, Gallega y Vasca 17, pp. 283-296.

Pereira Valcárcel, Manuel (1990): Poemas de cinza. Madrid: Edición do autor.

(2000): Rosa íntima. A Coruña: Espiral Maior.

(2001): Inventario de fragmentos. Santiago de Compostela: Follas Novas.

(2002): Libro das viaxes. Poio: Litoral das Rías.

(2005): Traxectos curtos. Santa Comba: tresCtres.

(2006): Todo morte. Sada: Ediciós do Castro.

(2007): Días do final. Vigo: Galaxia.

(2010): Malas cartas. Cesuras: Biblos.

(2012): Interior con froiteiro e feridas / Interior con frutero y heridas. Zaragoza: Aqua.

(2012): Tatuaxes / Tatuajes. Colmenar Viejo: Amargord. 
Regueiro Salgado, Begoña (2006): "Manuel Pereira Valcárcel: poesía de la Experiencia en la Galicia actual”, Madrygal. Revista de Estudios Gallegos 9, pp. 103-113.

(2012): "Manuel Pereira ou a poética da precisión", Revista de Lenguas y Literaturas Catalana, Gallega y Vasca 17, pp. 319-338.

(2014): "Descafeinado de máquina e conversas. Manuel Pereira Valcárcel”, Madrygal. Revista de Estudios Gallegos 17, pp. 255-260. 